University of Nebraska - Lincoln

DigitalCommons@University of Nebraska - Lincoln

\title{
Use of Infrared Thermography to Detect Thermographic Changes in Mule Deer (Odocoileus hemionus) Experimentally Infected with Foot-and-Mouth Disease
}

\author{
Mike R. Dunbar \\ Shylo R. Johnson \\ USDA-APHIS-Wildlife Services \\ Jack C. Ryan \\ USDA-APHIS-Wildlife Services \\ Matt McCollum \\ USDA-APHIS-Wildlife Services
}

USDA-APHIS-Wildlife Services, mike.r.dunbar@aphis.usda.gov

Follow this and additional works at: https://digitalcommons.unl.edu/icwdm_usdanwrc

Part of the Environmental Sciences Commons

Dunbar, Mike R.; Johnson, Shylo R.; Ryan, Jack C.; and McCollum, Matt, "Use of Infrared Thermography to Detect Thermographic Changes in Mule Deer (Odocoileus hemionus) Experimentally Infected with Footand-Mouth Disease" (2009). USDA National Wildlife Research Center - Staff Publications. 852.

https://digitalcommons.unl.edu/icwdm_usdanwrc/852

This Article is brought to you for free and open access by the U.S. Department of Agriculture: Animal and Plant Health Inspection Service at DigitalCommons@University of Nebraska - Lincoln. It has been accepted for inclusion in USDA National Wildlife Research Center - Staff Publications by an authorized administrator of DigitalCommons@University of Nebraska - Lincoln. 


\title{
USE OF INFRARED THERMOGRAPHY TO DETECT THERMO- GRAPHIC CHANGES IN MULE DEER (ODOCOILEUS HEMIONUS) EXPERIMENTALLY INFECTED WITH FOOT-AND-MOUTH DISEASE
}

\author{
Mike R. Dunbar, M.S., D.V.M., Shylo R. Johnson, M.S., Jack C. Rhyan, D.V.M., M.S., and \\ Matt McCollum, B.S.
}

\begin{abstract}
Infrared thermography (IRT) measures the heat emitted from a surface, displays that information as a pictorial representation called a thermogram, and is capable of being a remote, noninvasive technology that provides information on the health of an animal. Foot-and-mouth disease (FMD) caused by FMD virus (FMDV) is a severe, highly communicable viral disease of cloven-hoofed animals, including both domestic and wild ruminants. Early detection of the disease may reduce economic loss and loss of susceptible wildlife. The objective of this study was to evaluate the use of IRT to detect possible heat changes associated with sites of infection with FMDV in experimentally infected mule deer (Odocoileus hemionus). Infection occurred through either inoculation with FMDV or exposure to inoculated animals. Early vesicular lesions were observed on the mouth, feet, or both within $24 \mathrm{hrs}$ postinoculation and 48-96 hrs post-exposure. From internal temperature sensors, the exposed animals' body temperatures elevated significantly from the pre-infection temperature $\left(38.8^{\circ} \mathrm{C}, P \leq 0.002\right)$ starting the day before any lesions were observed. Body temperature was also found not to be significantly different from eye temperatures of well-focused thermograms. For feet thermograms, the mean of the daily maximum (MMAX) foot temperature rose significantly $(P=0.017)$ from two days before $\left(27.3^{\circ} \mathrm{C} \pm 1.9^{\circ} \mathrm{C}\right.$ SE) to the maximum MMAX observed $\left(33.0^{\circ} \mathrm{C} \pm 2.0^{\circ} \mathrm{C} \mathrm{SE}\right)$ at two days after the first foot lesion occurrence. These observed changes indicate that IRT may be a rapid, remote, and noninvasive method to screen for suspect animals in order to test further for FMDV infection during an FMD outbreak.
\end{abstract}

Key words: Foot-and-mouth disease, infrared, mule deer, Odocoileus hemionus, thermography, wildlife.

\section{INTRODUCTION}

Infrared thermography (IRT) measures the heat emitted from a surface and displays that information as a pictorial representation called a thermogram. Infrared medical imaging makes use of the fact that heat is one of the cardinal signs of inflammation, so an increase in body surface temperature may indicate inflammation of tissues underlying that point. In veterinary medicine, IRT has the advantage of being a remote, noninvasive technology that provides information on the health of an animal. It has been used in detecting lameness, as well as other inflammatory conditions in horses (Equus caballus), ${ }^{4}$ including subluxation of vertebra, abscesses,

From the United States Department of Agriculture, Animal and Plant Health Inspection Service, Wildlife Services, National Wildlife Research Center, 4101 LaPorte Avenue, Fort Collins, Colorado 80521, USA (Dunbar, Johnson); and the United States Department of Agriculture, Animal and Plant Health Inspection Service, Veterinary Services, National Wildlife Research Center, 4101 LaPorte Avenue, Fort Collins, Colorado 80521, USA (Rhyan, McCollum). Correspondence should be directed to Dr. Dunbar (mike.r.dunbar@ aphis.usda.gov). periostitis, and laminitis. ${ }^{9}$ IRT has also been used to detect infectious disease in other animals, including bovine viral diarrhea virus (BVDV) infection in young cattle (Bos taurus), ${ }^{12}$ bovine respiratory disease in cattle, ${ }^{11}$ rabies infection in raccoons (Procyon lotor) ${ }^{3}$ and foot-and-mouth disease (FMD) in cattle. ${ }^{10}$

Foot-and-mouth disease, caused by FMD virus (FMDV), is a severe, highly communicable viral disease and is the most feared disease of cattle in the world. Proposed economic losses, if an outbreak were to occur in Kansas, range from $\$ 35$ million to $\$ 1$ billion. ${ }^{7}$ The impacts of FMD are mainly to cattle and swine, but FMDV affects, and can be transmitted by, other clovenhoofed animals including domestic ruminants (i.e., sheep, goats) and wild ruminants. ${ }^{13,14}$ When an outbreak occurs in domestic livestock, susceptible wildlife may become infected. In the United States, an infection of mule deer (Odocoileus hemionus) in California occurred in 1924 concurrent with an FMD outbreak in cattle on the same range. In that outbreak, over 22,000 deer were killed to prevent the spread of the disease. Over $10 \%$ of the killed deer were found to have acute or chronic lesions consistent with FMD. ${ }^{5}$ This is the only known occurrence of wildlife being 
infected in the United States and, in 1929, the last outbreak of FMD in the U.S. occurred in cattle. ${ }^{2,13}$

Foot-and-mouth disease infection often starts with a high fever $\left(40-41^{\circ} \mathrm{C}\right.$ in cattle); vesicular lesions usually develop on the feet and mouth after an incubation period of 3 to 6 days. ${ }^{1,2}$ Because observable clinical signs are often preceded by a fever, and local inflammation may occur before or with lesion development, IRT may be a rapid, remote surveillance technique that can be utilized to detect suspect animals for clinical testing.

The objectives of the present study were to evaluate the use of IRT in detecting possible heat changes associated with sites of infection with FMDV, mainly the feet and oral region, in experimentally infected mule deer; and to identify if IRT has use as a potential rapid and remote screening technique to evaluate wild animals potentially infected with FMDV.

\section{MATERIALS AND METHODS}

Fourteen dam and hand-raised mule deer were used in this study. They were of mixed sex, 6 males and 8 females, and a year old at the time of the study, which was conducted in the spring. They were housed in bio-safety level 3 facilities at the Department of Homeland Security, Plum Island Animal Disease Center (PIADC), Orient, New York, USA $\left(41^{\circ} 10^{\prime} \mathrm{N}, 72^{\circ} 11^{\prime} \mathrm{W}\right)$ following protocols approved by the PIADC Institutional Animal Care and Use Committee. Thermograms were collected from the mule deer, which were undergoing an FMDV-pathogenesis study. Three containment rooms measuring $40 \mathrm{~m}^{2}$ were used. Temperatures in the rooms were maintained at 25 to $28^{\circ} \mathrm{C}$, and rooms underwent 23 to 30 air changes per hour.

For the pathogenesis study, two mule deer and one domestic steer (Bos taurus) were infected by intra-epithelial tongue inoculation with 10,000 bovine tongue infective doses of $\mathrm{O} 1$ Manisa FMDV. Inoculated animals were kept with four contact animals; two mule deer and two steers. After three days, exposed contact animals were placed in rooms with unexposed animals. The two contact mule deer were moved in with five mule deer and two steers, and the two contact steers were placed with five mule deer and one steer.

Before the initiation of the study at PIADC, 12 of the mule deer had very high frequency temperature transmitters (Advanced Telemetry Systems, Inc. [ATS], Isanti, Minnesota 55040,
USA) surgically implanted into the abdomen. Each implant continuously transmitted temperature data to a remote receiver, which recorded the data every half hour (Model R4500S, Dsp receiver with data logger; ATS). These temperatures were used as an index of body temperature and were compared with temperature data derived from the thermograms of the eye. To examine for fever, the daily maximum temperature for each deer was used in calculating the mean.

The animals were examined daily for lesions. Thermograms were taken, depending on staff availability, when the animals were examined using a forward-looking infrared camera (FLIR; Model ThermaCAM EX320; FLIR Systems, North Billerica, Massachusetts 01862, USA). Thermal temperature sensitivity for the ThermaCAM EX320 is $0.08^{\circ} \mathrm{C}$, and temperature accuracy is $\pm 2^{\circ} \mathrm{C}$. The FLIR camera settings used in the experiment were 1) palette: grey, 2) emissivity: $0.95,3)$ temperature measurement mode: area maximum, and 4) automatic and manual adjust temperature scale. A $25^{\circ}$ wide-angle lens was used throughout the experiment. The ThermaCAM QuickView Software (FLIR Systems) was used for storage, processing, and temperature analysis of the infrared data.

Each time thermograms were taken, two to three thermograms were taken of each animal consisting of rear feet, front feet, and head readings, including oral area and eye. Occasionally, all four feet were in the thermogram. Distance from camera to subject was between 1-3 m. Only focused thermograms are within the temperature sensitivity and accuracy range for the ThermaCAM EX320. Thus, only focused thermograms were used in the analysis. The maximum foot temperature of each foot for the deer was collected from the thermograms. From these temperatures, the mean maximum (MMAX) were calculated daily. Daily means were based on the first occurrence of lesions, which is listed as Day 0.

A one-factor repeated measures data structure $^{15}$ was used to evaluate changes in both foot and mouth IRT temperatures during the disease progression. To meet the assumptions of this test, only deer that had data from Day -2 to Day 2 were analyzed. ${ }^{8}$ If results were significant, analyses comparing each MMAX between days up to, and including, lesion occurrence were conducted using two-sample $t$-tests. To examine if eye temperatures were comparable to body temperatures, an analysis of variance was used to 


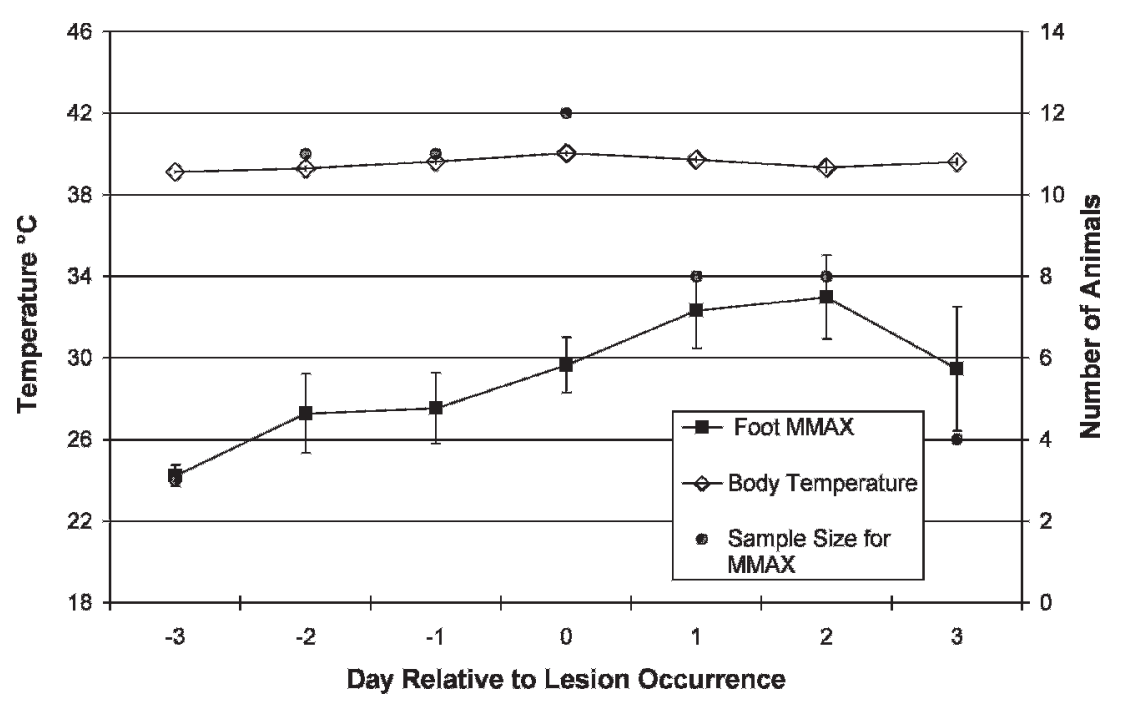

Figure 1. Comparison of the means $( \pm \mathrm{SE})$ of the maximum body temperature and the mean maximum foot temperature (MMAX) of mule deer (Odocoileus hemionus) during experimental infection with FMDV. For body temperatures, sample size was 12 until Day 2, when it dropped to 7 due to the loss of individuals. The foot sample size varied due to thermograms not taken of an animal and due to the loss of individuals.

examine if the difference between eye and body temperatures were different for different-quality thermograms, and a Bonferroni's corrected paired $t$-test was used to determine if the eye and body temperatures were similar for wellfocused thermograms. Body temperatures were also analyzed, using the paired $t$-test, to identify on which days the body temperature was elevated in relation to lesion occurrence from the preinfection maximum body temperature. A $P$ value of $<0.05$ was considered significant.

\section{RESULTS}

Early vesicular lesions at the injection site were observed within $24 \mathrm{hr}$ postinoculation (PI) for the two inoculated mule deer, and the first foot lesions were at $48 \mathrm{hr}$ postinoculation for the one inoculated deer that developed foot lesions. For the mule deer exposed through contact $(n=12)$, the first lesions for the mouth and the feet were observed 48-96 hr postexposure (PE). All of the exposed deer developed foot lesions.

\section{Body temperature}

Calculated from 9 days before any inoculation or exposure, the mean body temperature of the deer $(n=12)$ was $38.8^{\circ} \mathrm{C}\left( \pm 0.02^{\circ} \mathrm{C} \mathrm{SE}\right)$. After inoculation or exposure, the body temperatures were based on the first lesion occurrence of either the foot or mouth. The mean body temperature peaked at $40.0^{\circ} \mathrm{C}\left( \pm 0.1^{\circ} \mathrm{C} \mathrm{SE}\right)$ on the day the first lesions were evident and was $39.6^{\circ} \mathrm{C}\left( \pm 0.1^{\circ} \mathrm{C} \mathrm{SE}\right)$ and $39.7^{\circ} \mathrm{C}\left( \pm 0.1^{\circ} \mathrm{C} \mathrm{SE}\right) 1$ day before and after, respectively (Fig. 1). From the paired $t$-test, the maximum body temperatures PI or PE on Day -1 , Day 0 , and Day 1 were significantly different $(P \leq 0.002)$ from the pre-infection maximum body temperatures.

\section{Thermal Imagery}

Two hundred thirty-one thermograms were taken over 13 days. The mean number of images per animal per day was at $3.0( \pm 0.1)$, with a mean of $16.5( \pm 1.9)$ thermograms per animal and a mean of $17.8( \pm 3.8)$ thermograms per day.

Eye: The differences between thermographic eye temperature and body temperature, for the same hour for the same individual, were found to be dependent on the quality or focus of the thermograms $(F=6.50, P=0.0006, n=71)$. Because this difference was impacted by the quality of the thermogram, high-quality thermograms $(n=16)$ were compared to body temperature and were found not to be different $(P=0.19)$.

Mouth: Thermograms $(n=75)$ of the external area of the mouth of deer were evaluated for signs of heat associated with infection of FMDV. While five thermograms taken were excluded from analysis due to poor focus, this did not reduce the number of animals represented by the thermograms. Two days before the occurrence of 
mouth lesions, the mean mouth temperature was $35.6^{\circ} \mathrm{C}\left( \pm 0.1^{\circ} \mathrm{C} \mathrm{SE}, n=6\right)$, and it peaked at $36.2^{\circ} \mathrm{C}\left( \pm 0.5^{\circ} \mathrm{C} \mathrm{SE}, n=13\right)$ on the day of the first mouth lesions. Using the one-factor repeated design on the five deer with thermograms from Day -2 to Day 2, relative to first mouth lesion occurrence, no significant differences occurred among the mean daily thermal temperatures $\left(F_{4,16}\right.$ $=2.30, P=0.1$ ).

Feet: One hundred thirty-one thermograms were used in analyzing foot temperatures out of the 151 thermograms taken. The calculations for the mean temperatures were based on occurrence of the first foot lesion. The sample size, or number of deer contributing to the daily mean, varied due to staff availability, but this sample size was not influenced by excluding nonfocused thermograms from analysis. From 2 days (ca. $24 \mathrm{hr}$ PE) before any foot lesions were observed to 2 days after the first lesion occurrence, the MMAX foot temperature rose from $27.3^{\circ} \mathrm{C}$ $\left( \pm 1.9^{\circ} \mathrm{C} \mathrm{SE}, n=11\right)$ to $33.0^{\circ} \mathrm{C}\left( \pm 2.0^{\circ} \mathrm{C} \mathrm{SE}, n\right.$ $=8$ ) (Fig. 1). Using a single-factor repeated design on the seven deer with thermograms from Day -2 to Day 2, relative to first foot lesion occurrence, the MMAX temperature $\left(F_{4,24}=\right.$ 3.74, $P=0.017$ ) did statistically change over these days of the disease progression. This change, however, was not significant between Day -2 and Day $-1(P=0.93)$ nor between Day -1 and Day $0(P=0.29)$. Only three deer had thermograms taken 3 days before foot lesions occurred, and their MMAX was $24.2^{\circ} \mathrm{C}$ $\left( \pm 0.5^{\circ} \mathrm{C}\right)$.

\section{DISCUSSION}

Results of this study indicate that IRT has potential in screening for suspect animals for clinical examination of FMD. Mule deer experimentally infected with FMDV had a significant foot-temperature rise over the course of the infection. The increase in foot temperatures of these animals is probably associated with inflammation related to the development and occurrence of lesions. These temperature changes may have been associated with the severity of the lesion, the degree of viral infection before the development of the lesion, or both. However, the severity of the lesion and the degree of viral infection before the occurrence of foot lesions were not quantified.

The results of this study concerning the rise in foot temperatures of mule deer are similar to a study by Dunbar and Rhyan (unpubl. data) on pronghorn antelope (Antilocapra americana), in which pronghorns were also experimentally inoculated intradermally in the tongue with 10,000 lesion forming units of FMDV (O1 Manisa strain). In that study, fever, lameness, and early vesicular lesions on the feet were observed $42 \mathrm{hr}$ PI. Thermograms of the feet indicated increases in heat at $22 \mathrm{hr}$ PI, which was up to $20 \mathrm{hr}$ before clinical signs were observed. The results are also similar to the RainwaterLovett et al. ${ }^{10}$ study on FMD in cattle. They found that FMDV-infected cattle foot temperatures increased above the baseline temperatures at the preclinical and clinical stages.

At the other main site of lesion development, the mouth, IRT did not yield information that may be useful in screening for suspect animals. Even though lesions did develop within the oral cavity, the thermograms were of the outside of the mouth, where lesion development did not occur.

Thermograms of the eye may have use in detecting changes in general body temperature by use of the eye as an index of body temperature. Eye temperatures of the well-focused thermograms indicated a statistically similar temperature as the body temperature. Capturing quality thermograms improves with practice and with the user's familiarity with the equipment, as the camera used is a manual focus. Research that is focused on the correlation of eye temperature and body temperature will determine the practical use of this application. Because FMDV significantly elevated the deer's body temperature 1 day before occurrence of foot lesions, thermographic eye temperature may be useful in detecting if the animals have a fever. This is dependent on the development of using eye temperatures as an index of body temperature.

In comparison, Schaefer et al. ${ }^{12}$ found that IRT detected significant changes in temperatures of the orbit of domestic calves, and theses changes could be detected as early as 1 day PI of BVDV. They concluded that changes in orbital infrared temperatures appeared several days to $1 \mathrm{wk}$ before many objective laboratory tests and before changes in conventional clinical scores. They summarized that IRT has the advantage of being noninvasive, probably sensitive at an earlier state of infection, and of being unencumbered by the expense and time consumed by other biologic assessment techniques. Although fever is a characteristic of many infectious diseases, in the case of FMD detection, it would be important information in addition to other signs and would be relatively easy data to derive using IRT. 
Different factors may influence the accuracy of the thermographic temperatures recorded. Unfocused thermograms blur adjacent temperatures together, causing inaccurate temperatures. These were excluded from the analysis in this study; this did not, however, reduce the number of animals sampled when thermograms were taken, because multiple thermograms were taken of an animal. Distances beyond the spot:distance ratio will also combine adjacent temperatures together; if the ratio is $1: 250$ as in this study, a spot one unit (i.e., $1 \times 1 \mathrm{~cm})$ in size can accurately be measured up to 250 units (i.e., $250 \mathrm{~cm}$ or 2.5 meters) away. The animals were in a confined space for this study and, thus, the spot:distance ratio was not exceeded. Even if distances are too great for an accurate evaluation of absolute foot temperature, the comparison of relative temperatures of select areas of the animal, or an adjacent animal, using thermograms may be useful in deciding to pursue further evaluation.

Additional factors that may influence the accuracy of the temperature measured may include the amount of sunlight on the animal, cleanness of the area, and ambient temperature. These, and other, factors such as age, sex, activity level, injury, or other illness could also have an influence on the animal's temperature and will influence how the thermogram is evaluated. Under the experimental conditions of this study, these factors were minimized. However, more research is necessary to understand how these factors affect the temperatures measured by IRT and how much overlap there is among FMD thermograms and thermograms from other diseases and injuries. Even if the increased foot temperature of the FMDV-infected animals is similar to other diseases, responding to a thermogram with higher-than-expected foot temperatures, or to a "positive" thermogram, may allow a rapid response to the problem causing the foot temperature elevation.

Because an outbreak of FMD could have devastating effects, ${ }^{6,7}$ methods to aid in the detection of the disease should be pursued. During a diagnosed epizootic of FMD, every lame animal may be examined further for possible FMD infection. Screening animals with IRT may be treated the same, such that every animal with a hot foot is examined further for FMDV infection. In addition, some animals may present with hot feet before clinical signs of lameness are observed. Therefore, the addition of IRT as a screening tool may benefit programs aimed at eliminating this disease, as remote screening for suspect animals would reduce costs and time. For example, only animals with a positive thermogram may need to be captured for further examination, instead of capturing and handling large numbers of animals for examination. Also, because foot temperature may rise before the appearance of lesions, the possibility may exist to remove infected animals before lesion formation, thus possibly reducing transmission to other animals. This study indicates that IRT has the potential of being a rapid and remote screening technique to identify suspect animals potentially infected with FMD.

Acknowledgments: The authors would like to thank the staff of PIADC. Funding for this project was provided by United States Department of Agriculture, Animal and Plant Health Inspection Service, Wildlife Services and Veterinary Services.

\section{LITERATURE CITED}

1. Alexandersen, S., and N. Mowat. 2005. Footand-mouth disease: Host range and pathogenesis. In: Mahy, B. W. J. (ed.). Foot-and Mouth Disease Virus. Springer, New York, New York. Pp. 9-42.

2. Blood, D. C., O. M. Radostits, and J. A. Henderson. 1983. Veterinary Medicine: A Textbook of the Diseases of Cattle, Sheep, Pigs, Goats, and Horses, 6th ed. Bailliere Tindall, London, Great Britain.

3. Dunbar, M. R., and K. MacCarthy. 2006. Use of infrared thermography to detect signs of rabies infection in raccoons (Procyon lotor). J. Zoo Wildl. Med. 37: 518-523.

4. Eddy, A. L., L. van Hoogmoed, and J. R. Synder. 2001. A review of the role of thermography in the management of equine lameness. Vet. J. 162: 172-181.

5. Keane, C. 1927. The outbreak of foot and mouth disease among deer in the Stanislaus National Forest. California State Dep. Agric. Mon. Bull. 16: 213-226.

6. Kelly, A. M. 2005. Veterinary medicine in the $21 \mathrm{st}$ century: the challenge of biosecurity. ILAR J. 46: 62-64.

7. Pendell, D. L., J. Leatherman, T. C. Schroeder, and G. S. Alward. 2007. The economic impact of a foot-and-mouth disease outbreak: a regional analysis. J. Agric. Appl. Econ. 39. Available at: http://findarticles. com/p/articles/mi_qa4051/is_200710/ai_n21137539. Accessed 23 April 2008

8. Petrie, A., and P. Watson. 1999. Statistics for Veterinary and Animal Science. Blackwell Science Ltd., Malden, Massachusetts.

9. Purohit, R. C., and M. D. McCoy. 1980. Thermography in the diagnosis of inflammatory processes in the horse. Am. J. Vet. Res. 41: 1167-1174.

10. Rainwater-Lovett, K., J. M. Pacheco, C. Packer, and L. L. Rodriguez. 2009. Detection of foot-and-mouth disease virus infected cattle using infrared thermography. Vet. J. 180: 317-324. Available at: http://www. sciencedirect.com. Accessed 21 May 2008. 
11. Schaefer, A. L., N. J. Cook, J. S. Church, J. Basarab, B. Perry, C. Miller, and A. K. W. Tong. 2007. The use of infrared thermography as an early indicator of bovine respiratory disease complex in calves. Res. Vet. Sci. 83: 376-384.

12. Schaefer, A. L., N. Cook, S. V. Tessaro, D. Deregt, G. Desroches, P. L. Dubeski, A. K. W. Tong, and D. L. Godson. 2004. Early detection and prediction of infection using infrared thermography. Can. J. Anim. Sci. 84: 73-80.

13. Thomson, G. R., R. G. Bengis, and C. C. Brown. 2001. Pircornavirus infections. In: Williams, E.
S., and I. K. Barker (eds.). Infectious Diseases of Wild Mammals, 3rd ed. Iowa State Univ. Press, Ames, Iowa. Pp. 119-130.

14. Thomson, G. R., W. Vosloo, and A. D. S. Bastos. 2003. Foot and mouth disease in wildlife. Virus Res. 91: 145-161.

15. Winer, B. J., D. R. Brown, and K. M. Micheles. 1991. Statistical Principles in Experimental Design, 3rd ed. McGraw-Hill, Inc., New York, New York.

Received for publication 23 May 2008 